\title{
ERRATUM
}

\section{Inadequacy of 3-month Oswestry Disability Index outcome for assessing individual longer-term patient experience after lumbar spine surgery}

TO THE EDITOR: We appreciate the publication of our article, "Inadequacy of 3-month Oswestry Disability Index outcome for assessing individual longer-term patient experience after lumbar spine surgery" ( $\mathrm{J} \mathrm{Neu}$ rosurg Spine [epub ahead of print March 18, 2016; DOI: 10.3171/2015.11.SPINE15872]). On viewing the paper online, however, we noted that one of the departmental affiliations was incorrectly listed as "Orthopedics Surgery" when it should have been "Orthopaedic Surgery," and Dr. Kristin Archer was listed as having only one affiliation when in fact she has two. lows:

The corrected list of authors and affiliations is as fol-

Anthony L. Asher, MD, ${ }^{1}$ Silky Chotai, MD, ${ }^{2}$

Clinton J. Devin, MD, ${ }^{2}$ Theodore Speroff, $\mathrm{PhD},{ }^{4}$

Frank E. Harrell Jr., PhD,${ }^{3}$ Hui Nian, PhD, ${ }^{3}$ Robert

S. Dittus, MD, MPH, ${ }^{4,5}$ Praveen V. Mummaneni,

MD, ${ }^{6}$ John J. Knightly, MD, ${ }^{7}$ Steven D. Glassman,

MD ${ }^{8}$ Mohamad Bydon, MD, ${ }^{9}$ Kristin R. Archer,

PhD, DPT, ${ }^{2,10}$ Kevin T. Foley, MD,${ }^{11}$ and

Matthew J. McGirt, MD ${ }^{1}$

${ }^{1}$ Department of Neurological Surgery, Carolina

Neurosurgery and Spine Associates and

Neurological Institute, Carolinas Healthcare

System, Charlotte, North Carolina; ${ }^{2}$ Department

of Orthopaedic Surgery, Vanderbilt Spine

Center, Vanderbilt University Medical Center;

${ }^{3}$ Department of Biostatistics, Vanderbilt
University School of Medicine; ${ }^{4}$ Geriatric

Research Education Clinical Center, Tennessee

Valley Health System, Veterans Health

Administration; ${ }^{5}$ Departments of Medicine

and Biostatistics, Division of General Internal

Medicine and Public Health, Center for Health

Services Research, Vanderbilt University School

of Medicine, Nashville, Tennessee; ${ }^{6}$ Department

of Neurological Surgery, University of California,

San Francisco, California; ${ }^{7}$ Department of

Neurosurgery, Atlantic Neurosurgical Specialists,

Morristown, New Jersey; ${ }^{8}$ Department of

Orthopedic Surgery, University of Louisville and

the Norton Leatherman Spine Center, Louisville,

Kentucky; ${ }^{9}$ Department of Neurosurgery, Mayo

Clinic, Rochester, Minnesota; ${ }^{10}$ Department of

Physical Medicine and Rehabilitation, Vanderbilt

University Medical Center, Nashville; and

${ }^{11}$ Department of Neurosurgery, University of

Tennessee Health Sciences Center, Semmes-

Murphey Neurologic \& Spine Institute, Memphis,

Tennessee

Boldface type indicates corrections.

We apologize to the Editor and readers for the errors, and we appreciate the opportunity to correct them. The corrected version of the paper was posted online as of April 22, 2016, and appears in this issue.

Anthony L. Asher, MD

Carolinas Healthcare System, Charlotte, NC

CORRESPONDING ARTICLE See pp 170-180.

INCLUDE WHEN CITING

Published online April 22, 2016; DOI: 10.3171/2016.3.SPINE15872a.

CAANS, 2016 